
Pathophysiology of Haemostasis and Thrombosis

\title{
General Haemostatic Agents - Fact or Fiction?
}

\author{
Ulla Hedner \\ Novo Nordisk A/S, Copenhagen, Denmark
}

\section{Key Words}

Haemostasis failure $\cdot$ Thrombin · rFVIIa

\begin{abstract}
Haemophilia is the most serious bleeding model that nature has provided us with, indicating the importance of factor FVIII and FIX in haemostasis. According to current knowledge, haemostasis is initiated by the formation of a complex between tissue factor (TF), exposed as a result of a vessel wall injury, and activated FVII (FVIIa) that is normally present in circulating blood. The TF-FVIIa complexes convert FX into FXa on the TF-bearing cell. FXa then activates prothrombin into thrombin. This limited amount of thrombin activates FVIII, FV, FXI and platelets. Thrombin-activated platelets change shape, resulting in exposure of negatively-charged phospholipids, which form the perfect template for full thrombin generation involving FVIII and FIX. In patients with haemophilia FVIII or FIX is missing. These individuals generate only initial limited amounts of thrombin as its generation is dependent on the presence of FVIII and FIX. Full thrombin generation is necessary for complete activation of FXIII and thrombin activatable fibrinolytic inhibitor to occur. Furthermore, full thrombin generation is important for the fibrin structure of the haemostatic plug.
\end{abstract}

\section{KARGER}

Fax + 41613061234

E-Mail karger@karger.ch

www. karger.com
(C) 2002 S. Karger AG, Basel

$1424-8832 / 02 / 0327-0033 \$ 18.50 / 0$

Accessible online at:

www. karger.com/journals/pht
In the case of impaired thrombin generation, fibrin plugs will be loose and highly permeable. Such fibrin plugs are easily dissolved by normal fibrinolytic activity and thus prevent full and maintained haemostasis from occurring. The addition of rFVIIa to FVIII- or FIX-deficient plasma has been shown to increase thrombin generation in a cell-based in vitro model. Furthermore, extra rFVIIa was found to normalise fibrin clot permeability in vitro and to tighten the fibrin structure as studied by three-dimensional confocal microscopy. These findings indicate that administration of rFVIla is capable of compensating for the lack of FVIII and FIX. Accordingly, the administration of exogenous rFVIla has been found to stop bleedings in haemophilia patients and, provided it is given in doses high enough, to allow major surgery to be performed in severe haemophiliacs with inhibitors. As rFVIla enhances thrombin generation on already activated platelets, it has been suggested that rFVIla may also help to improve haemostasis in other situations involving impaired thrombin generation, such as platelet disorders (thrombocytopenia and functional platelet defects). Preliminary clinical data appear to support this. Patients with profuse bleeding due to extensive surgery or trauma often develop a complex coagulation pattern which includes reduced plasma levels of fibrinogen, FVIII and FV, and decreased platelet counts. These patients may

Prof. Ulla Hedner

Novo Nordisk A/S, Caritasgatan 19

S-21618 Malmo (Sweden)

Tel. +46 40 162869, Fax +46 40 162819, E-Mail uhe@novonordisk.com 
well have an impaired capacity to generate thrombin. Consequently, they may benefit from one or two doses of rFVIla in order to assist in the generation of a thrombin peak sufficient to form a firm, stable fibrin haemostatic plug and thereby reduce bleeding. This would facilitate any mechanical repair necessary for full haemostasis. Preliminary results in a few patients may support such an effect for rFVIla. As thrombin has such a crucial role in providing haemostasis, any agent that enhances the thrombin generation in situations with an impaired thrombin formation may be characterised as a 'general haemostatic agent'. Let us look forward to more 'facts' through the 'evidence-based route'.

Copyright @2002 S. Karger AG, Basel

\section{Introduction}

Failure of haemostasis is one of the most ominous events in clinical medicine. For the surgeon, it is potentially catastrophic and a number of haemostatic agents for topical use have been developed over the years. Haemostasis is the cumulative effect occurring as a result of many events. The vessels, platelets, the coagulation and the fibrinolytic systems are all involved. Defective platelets as well as lowered platelet counts result in an impaired thrombin generation and so does a defective coagulation system. Thrombin is necessary for haemostasis by converting the soluble fibrinogen into fibrin.

A number of agents are being used to achieve haemostasis. Such agents may be used topically or systemically. Topical haemostatic agents include vasoconstrictive agents such as epinephrine and procoagulant agents such as thrombin, 'haemostatic fibrin', gelatin, cellulose material for example spongostan. Systemically administered haemostatic agents include coagulation factors which can be used in situations of vitamin K deficiency where the vitamin K-dependent factors are low. The thrombin used so far is, however, bovine and development of cross-reacting antibodies against prothrombin and other coagulation proteins such as FV present in the thrombin solution have been reported [1, 2]. 'Haemostatic fibrin' also contains other coagulation proteins of bovine origin which may initiate the formation of cross-reacting antibodies. The use of gelatin and cellulose material are often restricted depending on clinical settings. A general haemostatic agent may be one that enhances full thrombin generation and thereby the formation of a stabile, tight fibrin haemostatic plug resistant to premature fibrinolysis.

\section{Normal Haemostasis}

According to current knowledge haemostasis is initiated by the formation of a complex between tissue factor (TF) exposed as a result of a vessel wall injury, and already activated FVII (FVIIa) normally present in the circulating blood in a concentration corresponding to about $1 \%$ of the total FVII protein mass [3]. The TF-FVIIa complexes convert FX into FXa on the TF bearing cell. FXa then activates prothrombin into thrombin $[4,5]$. This limited amount of thrombin activates FVIII, FV, FXI and platelets. Thrombin-activated platelets change shape and as a result will expose negatively charged phospholipids, which form the perfect template for full thrombin generation involving FVIII and FIX. Thrombin also converts the soluble fibrinogen into fibrin, it activates FXIII, the fibrin stabilizing enzyme, as well as the thrombin activatable fibrinolytic inhibitor (TAFI). The fibrin structure has been found to be dependent on the amount of thrombin formed and the rate of thrombin generation [6].

In summary, full generation of thrombin is necessary for the formation of a tight, stabile fibrin haemostatic plug resistant to premature fibrinolysis, which is required for full and sustained haemostasis.

\section{Recombinant FVIla in Patients with an Impaired Thrombin Generation}

\section{Haemophilia}

Haemophilia is the most serious bleeding model nature has provided us with. Patients with haemophilia lack FVIII or FIX and therefore, haemophilia patients only generate the initial limited amounts of thrombin and never get the full thrombin generation which is dependent on the presence of FVIII and FIX [7]. Recently, it was demonstrated that thrombin is generated on the surface of thrombin activated platelets in the absence of FIX provided extra FVIIa is added. Concentrations of FVIIa of at least $50 \mathrm{n} M$ are required to achieve thrombin amounts in the area of what is seen in the presence of FVIII/FIX [8, 9]. The FVIIa binding to the activated platelets is a low affinity binding and therefore, the amounts necessary for thrombin generation is many fold higher than the concentration of FVIIa normally present in the blood $(0.2 \mathrm{n} M)$. Using the same cell-based model as being used by Monroe et al., a dose response of the thrombin generation following the addition of increasing concentrations of rFVIIa was demonstrated [10]. Concentrations of rFVIIa of up to $150 \mathrm{n} M$ were required to achieve a similar thrombin gen- 
eration as seen in the presence of FVIII and FIX (in the absence of FXI). Furthermore, extra rFVIIa was found to normalize the fibrin clot permeability in vitro and to tighten the fibrin structure as studied by $3 \mathrm{D}$ confocal microscopy [11]. This would indicate that the administration of extra rFVIIa is capable of compensating for the lack of FVIII and FIX in the generation of a full thrombin generation and the formation of tight fibrin plugs resistant to premature lysis thereby initiating full and sustained haemostasis.

Accordingly, the administration of exogenous rFVIIa has been found to stop bleedings in haemophilia patients and, provided it is given in doses high enough, to allow major surgery in severe haemophiliacs with inhibitors [12].

\section{Other Situations Characterized by Impaired Thrombin Generation}

Based on the in vitro data indicating that rFVIIa enhances thrombin generation and thereby results in the formation of tight, and less porous fibrin structure, it may be hypothesized that the addition of extra rFVIIa may be beneficial in other situations than haemophilia with impaired thrombin generation. Defective thrombin generation is known to occur in patients with thrombocytopenia as well as in patients with functionally defective platelets [13]. Also, thrombin generation in the cell-based model was demonstrated to be dependent on the number of platelets present. Furthermore, the lag phase of the platelet activation was found to shorten in a dose-dependent manner after the addition of rFVIIa in the same model [14]. However, the thrombin peak did not normalize as a result of the added rFVIIa. It has, however, been stressed by Blombäck et al [6] that not only the amount of throm- bin but the rate of thrombin generation are also important for the formation of a tight fibrin structure. Preliminary clinical data seem to support a beneficial effect of extra rFVIIa in patients with bleedings and defective platelets $[15,16]$.

Potentially impaired thrombin generation may be involved in patients with a complex coagulation pattern as a result of massive bleedings in association with extensive surgery or trauma. Such patients often have lowered plasma levels of a number of various coagulation proteins such as fibrinogen, FVIII, FV etc. In addition, thrombocytopenia is common as well as an increased fibrinolysis as a result of massive tissue damage. Several of these factors are important for an adequate thrombin formation as well as for the formation of a tight fibrin plug. Thus, low levels of fibrinogen result in the formation of a loose fibrin structure and to a decreased activation of FXIII, the fibrin stabilizing factor [17]. These patients thus may benefit from one or two doses of rFVIIa in order to help to generate a thrombin peak, which may be enough to form a firm, stable fibrin haemostatic plug and thereby decrease the bleeding [9]. This would facilitate any mechanical repair necessary for full haemostasis. Preliminary results in a few patients may support such an effect of extra rFVIIa $[18,19]$.

Since thrombin has such a crucial role in providing haemostasis, any agent that enhances thrombin generation in situations with impaired thrombin formation may be characterized as a 'general haemostatic agent'.

\section{References}

1 Berruyer M, Amiral J, Ffrench P, Belleville J, Bastien O, Clerc J, Kassir A, Estanove S, Dechavanne M: Immunization by bovine thrombin used with fibrin glue during cardiovascular operations. Development of thrombin and factor $\mathrm{V}$ inhibitors. J Thorac Cardiovasc Surg 1993;105:892-897.

2 Chouhan VD, De La C, Nagaswami C, Weisel JW, Kajani M, Rao AK: Simultaneous occurrence of human antibodies directed against fibrinogen, thrombin, and factor $\mathrm{V}$ following exposure to bovine thrombin: Effects on blood coagulation, protein $\mathrm{C}$ activation and platelet function. Thromb Haemost 1997;77:343-349.
3 Wildgoose P, Nemerson Y, Hansen LL, Nielsen FE, Glazer S, Hedner U: Measurement of basal levels of factor VIIa in hemophilia A and B patients. Blood 1992;80:25-28.

4 Rapaport SI, Rao LV: Initiation and regulation of tissue factor-dependent blood coagulation. Arterioscler Thromb 1992;12:1111-1121.

5 Rapaport SI, Rao LV: The tissue factor pathway: How it has become a 'prima ballerina'. Thromb Haemost 1995;74:7-17.

6 Blomback B, Carlsson K, Fatah K, Hessel B, Procyk R: Fibrin in human plasma: Gel architectures governed by rate and nature of fibrinogen activation. Thromb Res 1994;75:521-538.
7 Hoffman M, Monroe DM, Oliver JA, Roberts HR: Factors IXa and Xa play distinct roles in tissue factor-dependent initiation of coagulation. Blood 1995;86:1794-1801.

8 Monroe DM, Hoffman M, Oliver JA, Roberts HR: Platelet activity of high-dose factor VIIa is independent of tissue factor. Brit $\mathrm{J}$ Haematol 1997;99:542-547.

9 Hedner U: NovoSeven as a Universal haemostatic agent. Blood Coagulation Fibrinolysis 2000;11(suppl 1):107-111.

10 Kjalke M, Ezban M, Hedner U: Increased initial thrombin generation may explain the efficacy of high-dose factor VIIa in thrombocytopenia. Blood 1999;94:451a. 
11 He S, Blomback M, Hedner U: Effect of rFVIIa on the permeability of fibrin gel. Thromb Haemost 2001;CD3315 (abstract).

12 Shapiro AD, Gilchrist GS, Hoots WK, Cooper HA, Gastineau DA: Prospective, randomised trial of two doses of rFVIIa (NovoSeven) in haemophilia patients with inhibitors undergoing surgery. Thromb Haemost 1998;80:773778.

13 Keularts IM, Beguin S, de Zwaan C, Hemker HC: Treatment with a GPIIb/IIIa antagonist inhibits thrombin generation in platelet rich plasma from patients. Thromb Haemost 1998; 80:370-371
14 Kjalke M, Ezban M, Monroe DM, Hoffman M, Roberts HR, Hedner U: High-dose factor VIIa increases initial thrombin generation and mediates faster platelet activation in thrombocytopenia-like conditions in a cell-based model system. Br J Haematol 2001;114:114-120.

15 Kristensen J, Killander A, Hippe E, Helleberg C, Ellegard J, Holm M, Kutti J, Mellqvist UH, Johansson JE, Glazer S, Hedner U: Clinical experience with recombinant factor VIIa in patients with thrombocytopenia. Haemostasis 1996;26(suppl 1):159-164.

16 Poon MC, Demers C, Jobin F, Wu JW: Recombinant factor VIIa is effective for bleeding and surgery in patients with Glanzmann thrombasthenia. Blood 1999;94:3951-3953.
17 McDonagh J, Fukue H: Determinants of substrate specificity for factor XIII. Semin Thromb Hemost 1996;22:369-376.

18 Kenet G, Walden R, Eldad A, Martinowitz U: Treatment of traumatic bleeding with recombinant factor VIIa. Lancet 1999;354:1879.

19 Martinowitz U, Holcomb JB, Pusateri AE, Stein M, Onaca N, Freidman M, Macaitis JM, Castel D, Hedner U, Hess JR: Intravenous rFVIIa administered for hemorrhage control in hypothermic coagulopathic swine with grade $\mathrm{V}$ liver injuries. J Trauma 2001;50:721-729. 